Arq. Bras. Med. Vet. Zootec., v.65, n.1, p.198-202, 2013

\title{
Composição química e valores energéticos de alimentos alternativos para leitões
}

\author{
[Chemical composition and energetic values of alternative feedstuffs for piglets] \\ W.R. Wesendonck ${ }^{1}$, V. Oliveira ${ }^{2 *}$, C.E. Gewehr ${ }^{3}$, Y.L. Silva ${ }^{4}$, L.A.F. Bordignon ${ }^{5}$ \\ ${ }^{1}$ Aluno de pós-graduação - Universidade Federal do Rio Grande do Sul - Porto Alegre, RS \\ ${ }^{2}$ Universidade Federal de Santa Maria - Santa Maria, RS \\ ${ }^{3}$ Universidade do Estado de Santa Catarina - Lages, SC \\ ${ }^{4}$ Universidade Estadual do Oeste do Paraná - UNIOESTE - Toledo, PR \\ ${ }^{5}$ Aluno de pós-graduação - Universidade Tecnológica Federal do Paraná - Dois Vizinhos, PR
}

\begin{abstract}
RESUMO
O presente experimento foi realizado para determinar a composição química e os valores energéticos de resíduo de bolacha $(\mathrm{RB})$, resíduo de wafer $(\mathrm{RW})$, resíduo de chocolate caramelizado (RCC) e resíduo de bombons e chocolates (RBC) para leitões. Foram utilizados 10 leitões castrados, com peso médio inicial

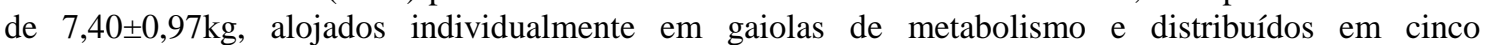
tratamentos: 1) dieta referência (DR); 2) $60 \% \mathrm{DR}+40 \% \mathrm{RB}$; 3) $60 \% \mathrm{DR}+40 \% \mathrm{RW}$; 4) $80 \% \mathrm{DR}+20 \%$ RCC; e 5) $80 \%$ DR $+20 \%$ RBC. O experimento foi repetido em três períodos consecutivos, com duração de 12 dias cada um, sendo sete destinados à adaptação e cinco destinados à coleta. Foi utilizada a metodologia de coleta total de fezes e urina e o óxido férrico como marcador fecal. $\mathrm{O}$ delineanento experimental utilizado foi o de blocos ao acaso, sendo o período utilizado como bloco. Os teores de proteína bruta foram de 7,96, 10,78, 6,33 e 4,01\% para RB, RW, RCC e RBC, respectivamente. O conteúdo de extrato etéreo do RB e do RW foi de 11,7 e 9,4\%, respectivamente. Já o do RCC e o do RBC apresentaram valores mais elevados, sendo 24,7 e $34,3 \%$, respectivamente. Os coeficientes de digestibilidade dos nutrientes e energia e o coeficiente de metabolizabilidade da energia foram semelhantes $(\mathrm{P}>0,05)$ entre os alimentos estudados. Os valores de energia digestível e metabolizável foram de 3914 e 3745; 4040 e 3767; 4454 e 4200; e 4937 e 4790kcal/kg para resíduo de bolachas, resíduo de wafer, resíduo de chocolate caramelizado e resíduo de bombons e chocolates, respectivamente. Conclui-se que os alimentos resíduo de bolachas, resíduo de wafer, resíduo de chocolate caramelizado e resíduo de bombons e chocolates apresentam potencial para serem incluídos em dietas pré-inicias e inicias de leitões.
\end{abstract}

Palavras-chave: suíno, digestibilidade, metabolismo

\begin{abstract}
The experiment was realized to determine the chemical composition and energetic values of cookie waste $(C W)$, wafer waste $(W W)$, caramel chocolate waste $(C C W)$ and candy and chocolate bar waste $(C C B W)$ using nursery piglets as an experimental model. Ten castrated piglets weighing $7.4 \pm 0.97 \mathrm{~kg}$ individually housed in a metabolic cage were used. The piglets were distributed in five treatments: 1) Reference diet $(R D)$; 2) $60 \% R D+40 \% C W ; 3) 60 \% R D+40 \% W W$; 4) $80 \% R D+20 \% C C W$; and, 5) $80 \% R D+20 \%$ $C C B W$. The experiment was repeated in three consecutive 12 day timeframes, being seven for adaptation and five for total collection of feces and urine. The ferric oxide was used as fecal marker. Randomized block design was used to compare the digestibility coefficients. Crude protein values were 7.96, 10.78, 6.33 and 4.01 for cookie flour, dry wafer, caramel chocolate and candy and chocolate bars, respectively. A high amount of ether extract was observed on cookie flour and dry wafer (11.7 and 9.4\%, respectively), however the chocolate by-products presented higher values $(24.7$ and $34.3 \%$, for caramel chocolate and
\end{abstract}

Recebido em 17 de agosto de 2012

Aceito em 25 de janeiro de 2013

*Autor para correspondência (corresponding author)

E-mail: v_olliveira@yahoo.com.br 
candy and chocolate bars, respectively). There was no difference ( $P>0.05)$ among digestibility coefficients of nutrients and energy and metabolizability energy coefficients among the feedstuff studied. The digestible and metabolisable energy values were 3914 and 3745; 4040 and 3767; 4454 and 4200; and, 4937 and $4790 \mathrm{kcal} / \mathrm{kg}$ for cookie flour, dry wafer, caramel chocolate and candy and chocolate bars, respectively. It is concluded that cookie flour, dry wafer, caramel chocolate and candy and chocolate bars have potential to be used in the diets of nursery pigs.

Keywords: pig, digestibility, metabolism

\section{INTRODUÇÃO}

O desmame representa um período crítico para o leitão devido a inúmeros fatores causadores de estresse, tais como separação da porca, mudança de ambiente, deficiência no controle ambiental, dificuldade de adaptação a comedouros e bebedouros, mistura com leitões de outras leitegadas e mudança de dieta (Rostagno e Pupa, 1998).

A alimentação adequada no período pósdesmama é fundamental e constitui um grande desafio aos nutricionistas, que precisam associar os aspectos fisiológicos e econômicos na elaboração de dietas para essa categoria animal (Ebert et al., 2005).

Tanto a composição química como os valores energéticos dos alimentos são informações que precisam estar disponíveis no momento da formulação (Ribeiro et al., 2010). A composição química permite saber quais os nutrientes que constituem os alimentos, evidenciando alguns de seus limites e potencialidades, enquanto os valores energéticos são indicadores da quantidade de energia liberada durante a oxidação metabólica.

A quantia de energia que o animal consegue extrair do alimento depende de fatores associados ao alimento e de fatores ligados ao animal, como, por exemplo, o peso vivo (Noblet et al., 2001; Sauvant et al., 2005). Nas primeiras semanas pós-desmama ocorrem muitas alterações na morfologia do trato gastrintestinal dos leitões (Vente-Spreeuwenberg et al., 2003), as quais podem comprometer a capacidade digestiva e absortiva de animais jovens. Considerando as particularidades da digestão dos leitões, é de grande importância determinar a digestibilidade dos alimentos utilizando-se animais jovens (Bertol e Ludke, 1997; Rostagno e Pupa, 1998; Bartels et al., 1999).
Assim, este experimento foi realizado com o objetivo de avaliar a composição química e os valores energéticos de resíduo de bolacha, resíduo de wafer, resíduo de chocolate caramelizado e resíduo de bombons e chocolates para leitões recém-desmamados.

\section{MATERIAL E MÉTODOS}

Foram utilizados 10 leitões machos castrados, desmamados aos 21 dias de idade e com

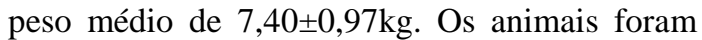
alojados individualmente em gaiolas de metabolismo, mantidas em sala com ambiente parcialmente controlado

Os alimentos foram avaliados utilizando-se cinco dietas experimentais: dieta referência (DR); dieta contendo $60 \%$ de DR e $40 \%$ de resíduo de bolacha (RB); dieta contendo $60 \%$ de DR e $40 \%$ de resíduo de wafer (RW); dieta contendo $80 \%$ de DR e $20 \%$ de resíduo de chocolate caramelizado (RCC); e dieta contendo $80 \%$ de DR e $20 \%$ de resíduo de bombons e chocolates (RBC). A dieta referência (Tab. 1) foi formulada para atender as exigências nutricionais sugeridas pelo NRC (National..., 1998). Os animais foram alimentados duas vezes ao dia, às oito e às 16 horas, e tiveram acesso à água à vontade.

Tabela 1. Composição química e valor de energia bruta da dieta referência (na matéria natural)

\begin{tabular}{lc}
\hline Característica & Valores \\
\hline Matéria seca $(\%)$ & 90,47 \\
Proteína bruta $(\%)$ & 19,20 \\
Extrato etéreo $(\%)$ & 5,99 \\
Matéria mineral $(\%)$ & 5,30 \\
Energia bruta $(\mathrm{kcal} / \mathrm{kg})$ & 4030 \\
\hline
\end{tabular}

$\mathrm{O}$ experimento foi dividido em três períodos, com duração de 12 dias cada, e os animais tiveram sete dias para adaptarem-se às gaiolas e às dietas experimentais, seguidos de cinco dias com coleta total de fezes e urina. A quantidade de dieta fornecida durante o período de coleta foi 
calculada com base no consumo do leitão com menor ingestão e ajustada para que todos os animais tivessem à disposição o mesmo conteúdo de alimento por unidade de peso metabólico (Sakomura e Rostagno, 2007). O início e o fim da coleta de fezes foram determinados incluindose $0,5 \%$ de óxido férrico $\left(\mathrm{Fe}_{2} \mathrm{O}_{3}\right)$ como marcador fecal. As fezes e a urina foram coletadas diariamente e, ao final do período experimental, foram pesadas, homogeneizadas, e as amostras foram retiradas e encaminhadas ao laboratório para análises químicas. A composição química dos ingredientes, das rações, das fezes e da urina foi analisada no Laboratório de Nutrição Animal da Unioeste, seguindo metodologias descritas em Silva e Queiroz (2005).

As médias dos coeficientes de digestibilidade da matéria seca, proteína bruta, energia bruta e energia digestível e metabolizável foram determinadas de acordo com a fórmula de Matterson et al. (1965). As médias foram submetidas à análise de variância utilizando-se o delineamento em blocos ao acaso e comparadas pelo teste de Tukey (5\%).

Este projeto foi aprovado pelo Comitê de Ética na Experimentação Animal e Aulas Práticas CEEAAP/UNIOESTE (Protocolo 1909).

\section{RESULTADOS E DISCUSSÃO}

$\mathrm{Na}$ Tab. 2 encontram-se os valores de composição química e de energia bruta dos alimentos estudados. O resíduo de bolachas (RB) apresentou composição química próxima à do resíduo de biscoito, citado em Rostagno et al. (2005), mas não próxima da obtida por Barbosa et al. (1999), em especial para proteína e extrato etéreo.

Tabela 2. Composição química de alimentos alternativos (na matéria natural) utilizados em dietas de leitões

\begin{tabular}{lcccc} 
Característica & $\begin{array}{c}\text { Resíduo de } \\
\text { bolacha }\end{array}$ & $\begin{array}{c}\text { Wafer } \\
\text { seco }\end{array}$ & $\begin{array}{c}\text { Chocolate } \\
\text { caramelizado }\end{array}$ & $\begin{array}{c}\text { Bombons e } \\
\text { chocolates }\end{array}$ \\
\hline Matéria seca (\%) & 94,06 & 92,54 & 96,05 & 98,84 \\
Proteína bruta (\%) & 7,96 & 10,78 & 6,33 & 4,01 \\
Extrato etéreo (\%) & 11,75 & 9,37 & 24,73 & 34,29 \\
Matéria mineral (\%) & 1,73 & 1,90 & 1,59 & 0,98 \\
Cálcio (\%) & 0,08 & 0,06 & 0,08 & 0,06 \\
Fósforo (\%) & 0,15 & 0,21 & 0,15 & 0,14 \\
Energia bruta (kcal/kg) & 4.734 & 4.708 & 5.510 & 5.896 \\
\hline
\end{tabular}

Não foram encontrados estudos com o resíduo de wafer (RW), mas os valores de composição química foram próximos dos verificados no RB. Contudo, comparando-se a composição do wafer destinado à alimentação humana (Lima et al., 2006), observa-se que o RW analisado apresentou o dobro de proteína e a metade do extrato etéreo (EE). A presença de outros resíduos da indústria de biscoitos, observados no lote de RW estudado, pode ter causado essas diferenças.

O valor de proteína bruta do resíduo de chocolate caramelizado (RCC) foi dois pontos percentuais superior ao encontrado no resíduo de bombons e chocolates (RBC). Por outro lado, o RCC apresentou valor de extrato etéreo 10 pontos percentuais inferior ao RBC. Destacam-se os altos valores de EE, tanto do RCC como do $\mathrm{RBC}$, que foram de, aproximadamente, $25 \% \mathrm{e}$ $35 \%$, respectivamente. McNaughton et al. (1997) avaliaram a utilização de resíduo de chocolate na alimentação de suínos e constataram valores de 4,7 e $18,6 \%$ para proteína e extrato etéreo, respectivamente.

Na Tab. 3 estão os valores dos coeficientes de digestibilidade (CD) da matéria seca (CDMS), proteína bruta (CDPB), energia bruta (CDEB) e do coeficiente de metabolizabilidade da energia bruta (CMEB). 
Tabela 3. Valores dos coeficientes de digestibilidade dos alimentos alternativos (na matéria seca) utilizados em dietas para leitões

\begin{tabular}{ccccccc} 
Variável & $\begin{array}{c}\text { Resíduo } \\
\text { de bolacha }\end{array}$ & $\begin{array}{c}\text { Wafer } \\
\text { seco }\end{array}$ & $\begin{array}{c}\text { Chocolate } \\
\text { caramelizado }\end{array}$ & $\begin{array}{c}\text { Bombons e } \\
\text { chocolates }\end{array}$ & EPM & $\begin{array}{c}\text { Efeito do } \\
\text { tratamento }\end{array}$ \\
\hline CDMS (\%) & 92,27 & 92,56 & 90,45 & 88,65 & 4,96 & NS \\
CDPB (\%) & 78,29 & 82,32 & 82,84 & 83,29 & 8,13 & NS \\
CDEB (\%) & 90,25 & 91,97 & 91,70 & 91,01 & 4,53 & NS \\
CMEB (\%) & 86,33 & 85,88 & 86,49 & 88,29 & 5,53 & NS \\
\hline
\end{tabular}

$\mathrm{CDMS}=$ coeficiente de digestibilidade da matéria seca; $\mathrm{CDPB}=$ coeficiente de digestibilidade da proteína bruta; $\mathrm{CDEB}=$ coeficiente de digestibilidade da energia bruta; $\mathrm{CMEB}=$ coeficiente de metabolizabilidade da energia bruta. EPM=erro-padrão da média. NS= não significativo.

Não houve diferenças $(\mathrm{P}>0,05)$ entre os CDMS dos alimentos analisados e foram observados valores mais altos que $88,5 \%$, que é próximo ao obtido para milho $(90,0 \%)$ utilizado para leitões na fase inicial como modelo experimental (Bertol e Ludke, 1997).

Os CDPB dos alimentos analisados foram semelhantes $(\mathrm{P}>0,05)$ e apresentaram média de $81,7 \%$. Ao se observar especificamente o CDPB do $\mathrm{RB}$, constata-se que o valor $(78,3 \%)$ foi inferior aos valores de 83,0 e $84,4 \%$, citados em Rostagno et al. (2005) e Santos et al. (2005). No presente estudo, os CDPB foram determinados com leitões na fase de creche, enquanto os valores citados anteriormente foram determinados com animais acima de $40 \mathrm{~kg}$ de peso vivo. Assim, o trato digestivo menos desenvolvido dos animais jovens pode ter contribuído para os valores inferiores encontrados nesses estudo (Bertol e Ludke,
1997). É evidente que diferenças comumente observadas entre lotes de subprodutos e resíduos também podem ter contribuído para as discrepâncias (Fialho, 2009).

Os CDEB foram semelhantes $(\mathrm{P}>0,05)$ entre os alimentos. Todos os valores foram superiores a $90 \%$, o que indica que a energia dos alimentos estudados é altamente digestível. Os resultados de Bertol e Ludke (1997), obtidos com leitões, reforçam essa ideia, pois alimentos reconhecidamente de alto valor nutricional, como a lactose e o leite desnatado em pó, apresentaram CDEB acima de $90 \%$.

O conteúdo de energia digestível (ED) e o de energia metabolizável (EM) foram elevados e evidenciam a capacidade dos alimentos analisados em fornecer energia para a manutenção e o crescimento dos leitões (Tab. 4).

Tabela 4. Valores de nutrientes e energia digestível e energia metabolizável (na matéria seca) de alimentos alternativos utilizados na dieta de leitões

\begin{tabular}{lccccc}
\hline Variável & $\begin{array}{c}\text { Resíduo de } \\
\text { bolacha }\end{array}$ & $\begin{array}{c}\text { Wafer } \\
\text { seco }\end{array}$ & $\begin{array}{c}\text { Chocolate } \\
\text { caramelizado }\end{array}$ & $\begin{array}{c}\text { Bombons e } \\
\text { chocolates }\end{array}$ & EPM \\
\hline MSD $(\%)$ & 84,54 & 86,22 & 81,57 & 83,85 & 4,58 \\
PD $(\%)$ & 6,23 & 8,87 & 5,24 & 3,34 & 0,47 \\
ED $(\mathrm{kcal} / \mathrm{kg})$ & 3914 & 4040 & 4454 & 4937 & 274 \\
EM $(\mathrm{kcal} / \mathrm{kg})$ & 3745 & 3767 & 4200 & 4790 & 225 \\
\hline
\end{tabular}

$\mathrm{MSD}=$ matéria seca digestível; $\mathrm{PD}=$ proteína digestível; $\mathrm{ED}=$ =energia digestível; $\mathrm{EM}=$ =energia metabolizável.

No caso do RB, os dados de ED obtidos neste experimento foram 4,5 e $8 \%$ superiores aos obtidos por Barbosa et al. (1999) e Santos et al. (2005), respectivamente. Essas diferenças podem estar associadas ao conteúdo de extrato etéreo dos lotes avaliados em cada um dos experimentos, pois, no presente estudo, o valor de extrato etéreo do RB foi de $11,7 \%$, enquanto no estudo de Barbosa et al. (1999) esse valor foi de $6,5 \%$. Também foi observada correlação linear significativa $(\mathrm{P}<0,05)$ entre os conteúdos de EE e os valores de ED e EM, o que era esperado, pois sabe-se que os lipídeos liberam uma grande quantidade de energia durante sua oxidação metabólica (NRC, 1998).

Pelos resultados obtidos, recomenda-se que sejam realizados experimentos para determinação de níveis ótimos de inclusão dos 
alimentos utilizados neste estudo nas dietas de leitões.

\section{CONCLUSÃO}

Os alimentos resíduo de bolachas, resíduo de wafer, resíduo de chocolate caramelizado e resíduo de bombons e chocolates apresentam potencial para serem incluídos em dietas préinicias e inicias de leitões.

\section{REFERÊNCIAS}

BARBOSA, H.P.; TRINDADE NETO, M.A.; SORDI, I.M.P. et al. Coeficientes de digestibilidade e valores energéticos de alguns alimentos para suínos. Bol. Indúst. Anim., v.56, p.47-52,1999.

BARTELS, H.; PIRES, F.; BECKER, B. et al. Metabolismo do jejum e retenção de nitrogênio pelos leitões desmamados aos 14 ou aos 21 dias de idade. In: CONGRESSO BRASILEIRO DE VETERINÁRIOS ESPECIALISTAS EM SUINOCULTURA, 1., 1999, Belo Horizonte. Anais... Belo Horizonte: CNPSA/EMBRAPA, 1999. p.419-420.

BERTOL, T.M.; LUDKE, J.V. Determinação do balanço de energia e nitrogênio de alguns alimentos com leitões na fase inicial. In: CONGRESSO BRASILEIRO DE VETERINÁRIOS ESPECIALISTAS EM SUINOCULTURA, 8., 1997, Foz do Iguaçu. Anais... Foz do Iguaçu: CNPSA/EMBRAPA, 1997. p.347-348.

EBERT, A.R.; RIBEIRO, A.M.L.; KESSLER, A.M. Desempenho e digestibilidade de leitões recém desmamados recebendo grãos de arroz, milho ou RB de trigo escuro. Arch. Latinoamericanos Prod. Anim., v.13, p.43-50, 2005.

FIALHO, E.T. Alimentos alternativos para suínos. Lavras: Editora UFLA. 2009. 232p.

LIMA, D.M.; COLUGNATI, F.A.B.; PADOVANI, R.M. et al. Tabela Brasileira de Composição de Alimentos. Versão II. 2. ed., Campinas, SP: NEPA-UNICAMP, 2006. 113p.

MATTERSON, L.D.; POTTER, L.M.; STUTZ, M.W. The metabolisable energy of feed ingredients for chickens. Res. Rep., v.7, p.11-14, 1965.
McNAUGHTON, E.P.; BALL, R.O.; FRIENDSHIP, R.M. The effects of feeding a chocolate product on growth performance and meat quality of finishing swine. Can. J. An. Sc., v.77, p.1-8, 1997.

NATIONAL research council - NRC. Nutrient requirements of swine. 10.ed. Washington,D.C.: National Academy Press, 1998. p.93.

NOBLET, J. Estimativas do valor energético em rações de suínos. In: WORKSHOP LATINOAMERICANO AJINOMOTO BIOLATINA, 1., 2001, Foz do Iguaçu. Anais... Foz do Iguaçu: Ajinomoto Animal Nutrition, 2001. p.2-16.

RIBEIRO, A.M.L.; HENN, J.D.; SILVA, G.L. Alimentos alternativos para suínos em crescimento e terminação. A. Sci. Vet., v.38, Supl. 1, p.61-71, 2010

ROSTAGNO, H.S.; PUPA, J.M.R. Fisiologia da digestão e alimentação de leitões. In: SIMPÓSIO SOBRE NUTRIÇÃO E MANEJO DE LEITÕES, 1998, Campinas. Anais... Campinas: CBNA, 1998. p.60-87.

SAKOMURA, N.K.; ROSTAGNO, H.S. Métodos de pesquisa em nutrição de monogástricos. Jaboticabal: Funep, 2007. 283p.

SANTOS, Z.A.S.; FREITAS, R.T.F.F.; FIALHO, E.T. et al. Valor nutricional de alimentos para suínos determinado na Universidade Federal de Lavras. Cienc. e Agrot., v.29, p.232-237, 2005.

SAUVANT, D.; PEREZ, J.M.; TRAN, G. Tables of composition and nutritional value of feed materials. Wageningen Academic Publishers. INRA editions. 2004. 304p.

SILVA, D.J.; QUEIROZ, A.C. Análise de alimentos: métodos químicos e biológicos. 3.ed. Viçosa, MG: Universidade Federal de Viçosa, 2005. 235p.

VENTE-SPREEUWENBERG, J.M.A.J.; VERDONK, J.M.; VERSTEGEN, M.W.A.; BEYNEN, A.C. Villus height and gut development in weaned piglets receiving diets containing either glucose, lactose or starch. Brit. J. Nut., v.90, p.907-913, 2003. 